\title{
Research Paper Taxane \& cyclophosphamide vs anthracycline \& taxane-based chemotherapy as adjuvant treatment for breast cancer: a pooled analysis of randomized controlled trials by the Hellenic Academy of Oncology
}

\author{
Panagiotis Ntellas ${ }^{1,2}$, Nikolaos Spathas ${ }^{3}$, Sofia $_{\text {Agelaki }}^{4}$, Elias Zintzaras ${ }^{2}$ and \\ Emmanouil Saloustros ${ }^{5}$ \\ ${ }^{1}$ Department of Medical Oncology, University Hospital of Ioannina, Ioannina, Greece \\ ${ }^{2}$ Department of Biostatistics and Clinical Bioinformatics, Faculty of Medicine, University of Thessaly, Larissa, Greece \\ ${ }^{3}$ 2nd Department of Medical Oncology, University Hospital Attikon, Athens, Greece \\ ${ }^{4}$ Department of Medical Oncology, University General Hospital of Heraklion, Heraklion, Crete, Greece \\ ${ }^{5}$ Department of Oncology, University General Hospital of Larissa, Larissa, Greece \\ Correspondence to: Emmanouil Saloustros, email: esaloustros@med.uth.gr \\ Keywords: early breast cancer; adjuvant; anthracycline; taxane; non-Inferiority
}

Received: November 12, $2018 \quad$ Accepted: December 16, $2018 \quad$ Published: February 05, 2019

Copyright: Ntellas et al. This is an open-access article distributed under the terms of the Creative Commons Attribution License 3.0 (CC BY 3.0), which permits unrestricted use, distribution, and reproduction in any medium, provided the original author and source are credited.

\section{ABSTRACT}

Background: Adjuvant chemotherapy has an indisputable value for early breast cancer patients. Anthracycline and taxane-based regimens (TaxAC) have not been proven superior to taxane \& cyclophosphamide (TC), a less toxic combination. Our objective was to estimate the cumulative evidence for non-inferiority of TC against TaxAC, in the adjuvant setting of patients with HER2-negative, breast cancer.

Results: Overall, 7,341 patients were included in this analysis. Superiority of TaxAC or non-inferiority of TC was not established either for the overall population (DFS HR, 1.11; 95\% CI, 0.95-1.30; $p=0.18$ ), or for the node-negative patients (HR, $1.05 ; 95 \% \mathrm{CI}, 0.82-1.34 ; p=0.71$ ). A difference in DFS of $1.28 \%$ (TC DFS, $89.04 \%$; 95\% CI, 88\%-90\% \& TaxAC DFS, 90.32\%; 95\% CI, 89\%-91\%) was found in favor of TaxAC. Lower risk of death was not established for either treatment regimen (OSHR, 1.02; 95\% CI, $0.82-1.25 ; p=0.88$ ). Overall, the toxicity profile favored TC.

Conclusion: Although non-inferiority of TC was not proven, superiority of TaxAC is still questioned. The present analysis narrows the risk of recurrence between the treatment groups. Considering TC has a more favorable safety profile, the question as to which treatment regimen should be preferred under what circumstances, needs to be individualized according to patients' characteristics and desires.

Methods: Treatment efficacy data from The ABC trials, the Plan B trial and a trial by the Hellenic Oncology Research group (HORG) were pooled. Disease free survival (DFS) and overall survival (OS) were scrutinized. A HR of 1.18 for TC versus TaxAC was chosen to demonstrate inferiority.

\section{INTRODUCTION}

Breast cancer is the most common malignant tumor and the second cause of cancer related death in women [1-3]. Early breast cancer (EBC) [4] defined as the absence of malignant spread beyond the breast and the axillary lymph nodes is the stage of the disease most frequently diagnosed [1]. The implementation of adjuvant therapy based on combinations of cytotoxic drugs, endocrine and biologic therapies for the eradication of microscopic 
systemic disease, has a major impact on recurrence, disease-free survival (DFS) and overall survival (OS) of women with EBC [5-10].

The type of adjuvant therapy is based upon both tumor (i.e. histology, stage, HER 2 \& endocrine receptors status, recurrence risk score) and patient characteristics (i.e. age, menopausal status, comorbidities). Before deciding for the administration of adjuvant chemotherapy physicians balance the individual risk of recurrence and the relative risk reduction, with the toxicity of the treatment. $[8,11]$.

Anthracycline-based combinations have been used in the treatment of early breast cancer for more than three decades [8] and are generally more effective than earlier combinations like the cyclophosphamidemethotrexate-fluorouracil (CMF) regimen [9, 12]. Along with anthracyclines, taxanes have emerged as particularly active cytotoxics against breast cancer [13]. Adjuvant polychemotherapy with taxanes given concurrently or sequentially with anthracyclines has resulted in reduced recurrence and mortality rates compared to anthracyclinebased regiments alone $[6,8,10]$. Consequently, taxaneanthracycline combinations are now widely used as adjuvant chemotherapy both for Her2-negative and Her2positive early breast cancer $[6,8,14]$.

Nevertheless, safety concerns regarding cardiotoxicity and secondary malignancies linked to anthracycline use, along with promising data from taxanebased, non-anthracyclines containing regimens have called the role of anthracyclines into doubt [8]. A less toxic nonanthracycline regimen is very appealing both for physicians and patients, especially those with reduced physiological reserves and significant comorbidities such as the elderly population [13]. The docetaxel-cyclophosphamide (TC) combination is a non-anthracycline containing regimen that has demonstrated superior efficacy in terms of DFS and OS compared to doxorubicin-cyclophosphamide (AC) [15-17]. However, AC is considered obsolete with contemporary standards [5] and $\mathrm{AC}$ in sequence or concurrent with a taxane (TaxAC) is usually preferred to treat high risk patients $[8,15,18-20]$.

To date, three major studies have addressed the efficacy of TC compared to TaxAC for early stage HER2negative breast cancer; namely the $\mathrm{ABC}$ trials, the WSG Plan B trial and the Hellenic Oncology Research Group (HORG) trial, demonstrating mixed results $[5,21,22]$. In such a situation, a pooled analysis of the available data may help resolve controversial issues given its capacity to provide more accurate, usually with narrower confidence interval (CI), estimates of the treatment effect and could also identify the causes of heterogeneity among different trials [6]. In this study we aimed to address the cumulative evidence for non-inferiority of the anthracycline-free regimen TC against TaxAC in the adjuvant setting of patients with HER2-negative, invasive breast cancer.

\section{RESULTS}

\section{Study characteristics and patients' demographics}

The efficacy outcomes of the ABC trials and the HORG trial were published in 2017 and 2016 respectively, whereas the WSG Plan B trial was presented in the American Society of Clinical Oncology (ASCO) annual meeting in 2017. All of the included trials had a matching experimental arm that consisted of docetaxel $\left(75 \mathrm{mg} / \mathrm{m}^{2}\right)$ and cyclophosphamide $\left(600 \mathrm{mg} / \mathrm{m}^{2}\right)$ for 6 cycles (TC). In the HORG trial, the comparison arm consisted of epirubicin $\left(75 \mathrm{mg} / \mathrm{m}^{2}\right), 5$-fluorouracil $\left(500 \mathrm{mg} / \mathrm{m}^{2}\right)$ and cyclophosphamide $\left(500 \mathrm{mg} / \mathrm{m}^{2}\right)$ for four cycles, followed by four cycles of docetaxel $\left(75 \mathrm{mg} / \mathrm{m}^{2}\right)$. In the WSG Plan B trial, the comparison arm consisted of epirubicin $\left(90 \mathrm{mg} / \mathrm{m}^{2}\right)$ and cyclophosphamide $\left(500 \mathrm{mg} / \mathrm{m}^{2}\right)$ for four cycles, followed by 4 cycles of docetaxel $\left(100 \mathrm{mg} / \mathrm{m}^{2}\right)$. Among the $\mathrm{ABC}$ trials, in the USOR 03-090 trial, the anthracycline arm consisted of docetaxel $\left(75 \mathrm{mg} / \mathrm{m}^{2}\right)$, doxorubicin $\left(50 \mathrm{mg} / \mathrm{m}^{2}\right)$ and cyclophosphamide $\left(500 \mathrm{mg} / \mathrm{m}^{2}\right)$ for 6 cycles (TAC); in the B-46-I/USOR 07132 trial, patients were randomized to receive TC, TAC or TC plus Bevacizumab, but only data concerning the comparison of TC to TAC were analyzed; finally, in the NSABP B-49 trial patients in the anthracycline arm were given a choice between TAC for 6 cycles, or AC every 3 weeks for four cycles followed by paclitaxel $\left(80 \mathrm{mg} / \mathrm{m}^{2}\right)$ weekly for 12 doses, or AC every 2 weeks for four cycles followed by paclitaxel $\left(80 \mathrm{mg} / \mathrm{m}^{2}\right)$ weekly for 12 doses, or AC every 2 weeks for four cycles followed by paclitaxel $\left(175 \mathrm{mg} / \mathrm{m}^{2}\right)$ every 2 weeks for four cycles. Median follow-up was 3.3 years for the ABC trials, 3.9 years for the HORG trial, and 5 years for the WSG-Plan B trial.

A total of 8.688 patients were collectively enrolled in the trials. Overall, 7.341 patients, that composed the intention to treat (ITT) population, were available for the pooled analysis; ultimately, only 6.881 patients completed the intended treatment (see Figure 1. Flowchart). Patients characteristics and survival are illustrated in Table 1. Breast conserving surgery was the preferred method of surgical treatment. Cumulatively, 3,660 patients had grade I/II tumors and 3,390 patients had grade III. Estrogen receptors were positive in tumors from 5,444 patients, while only 1,807 patients had ER-negative tumors. 3,144 patients had no infiltrated lymph nodes; 1 to 3 positive lymph nodes were detected in 3,074 patients; 4 to 9 positive lymph nodes were detected in 812 patients and only 264 patients had more than 10. Throughout, most breast cancer patients had up to three lymph nodes infiltrated. Also, $63 \%$ of the included patients were post-menopause.

\section{Primary endpoint (disease free survival)}

Primary focus of this analysis was to determine if the anthracycline-free regimen TC is non-inferior to 
TaxAC with regards to DFS. By combining the available ITT data (7,341 patients) we found a pooled-fixed effect HR of 1.08 (95\% CI, 0.92-1.26, $p=0.35)$. The result did not demonstrate a statistically significant difference of the treatment effects of TC and TaxAC on DFS, meaning that no treatment regimen was found to be superior to the other. However, the upper limit of the 95\% CI from the pooled analysis exceeded the non-inferiority threshold of 1.18, thus non-inferiority of TC could not be proven (Figure 2. Disease Free Survival). Synthesis of the available data for the rate of survival at the 5th, 4th and 3rd year for the Plan B, ABC and HORG trials respectively produced a pooled DFS rate of $89.04 \%(95 \%$ CI, 88\% - 90\%) for TC and 90.32\% (95\% CI, 89\%-91\%) for TaxAC, indicating an absolute difference in survival of $1.28 \%$ in favor of TaxAC. Fixed effects was the selected model as indicated by the absence of heterogeneity ( $Q$-test $p=0.34, \mathrm{I}^{2}=7 \%$ ), which was as expected considering the relative consistency of the patients characteristics between the RCTs. No statistically significant publication bias was detected by Egger's test $(p=0.9)$, while visual inspection of the funnel plot revealed no evidence of asymmetry (Supplementary Figure 1. Publication Bias).

\section{Secondary endpoints (overall survival, node- negative patients)}

The available survival data from the 7,341 patients were combined to determine the treatment effect on overall survival; pooled analysis yielded a fixed-effects HR of $1.02(95 \% \mathrm{CI}, 0.82-1.25, p=0.88)$. At the time point that this analysis was carried out, no statistically significant difference was found between the treatment regimens in terms of overall survival (Supplementary Figure 2. Overall Survival \& Node-Negative DFS). Between study heterogeneity was not observed ( $Q$-test $\left.p=0.80, \mathrm{I}^{2}=0 \%\right)$.

Out of the 3 studies only ABC trials and Plan B trial included patients without infiltrated lymph nodes. Overall, the available survival data from 3,127 patients were included in the subgroup pooled-analysis of the treatment effect on DFS for the lymph node negative population and provided a fixed-effects HR for DFS of 1.05 (95\% CI, 0.82-1.34; $p=0.77)$; The difference found on DFS for the node-negative population was not statistically significant, however, non-inferiority of TC could not be proven (Supplementary Figure 2. Overall Survival \& Node-Negative DFS). No heterogeneity was observed between the studies $\left(Q\right.$-test $\left.p=0.88, \mathrm{I}^{2}=0 \%\right)$.

\section{Toxicity}

Pooled toxicity analysis from all 5 RCTs is listed in Table 2. Neutropenia, mostly grade 3-4, was common in both groups. Anemia was frequently observed but didn't seem to pose much of a problem since mainly grade 1-2 events were reported, with a higher rate, in the TaxAC group $(\mathrm{OR}=1.3, p=0.001)$.

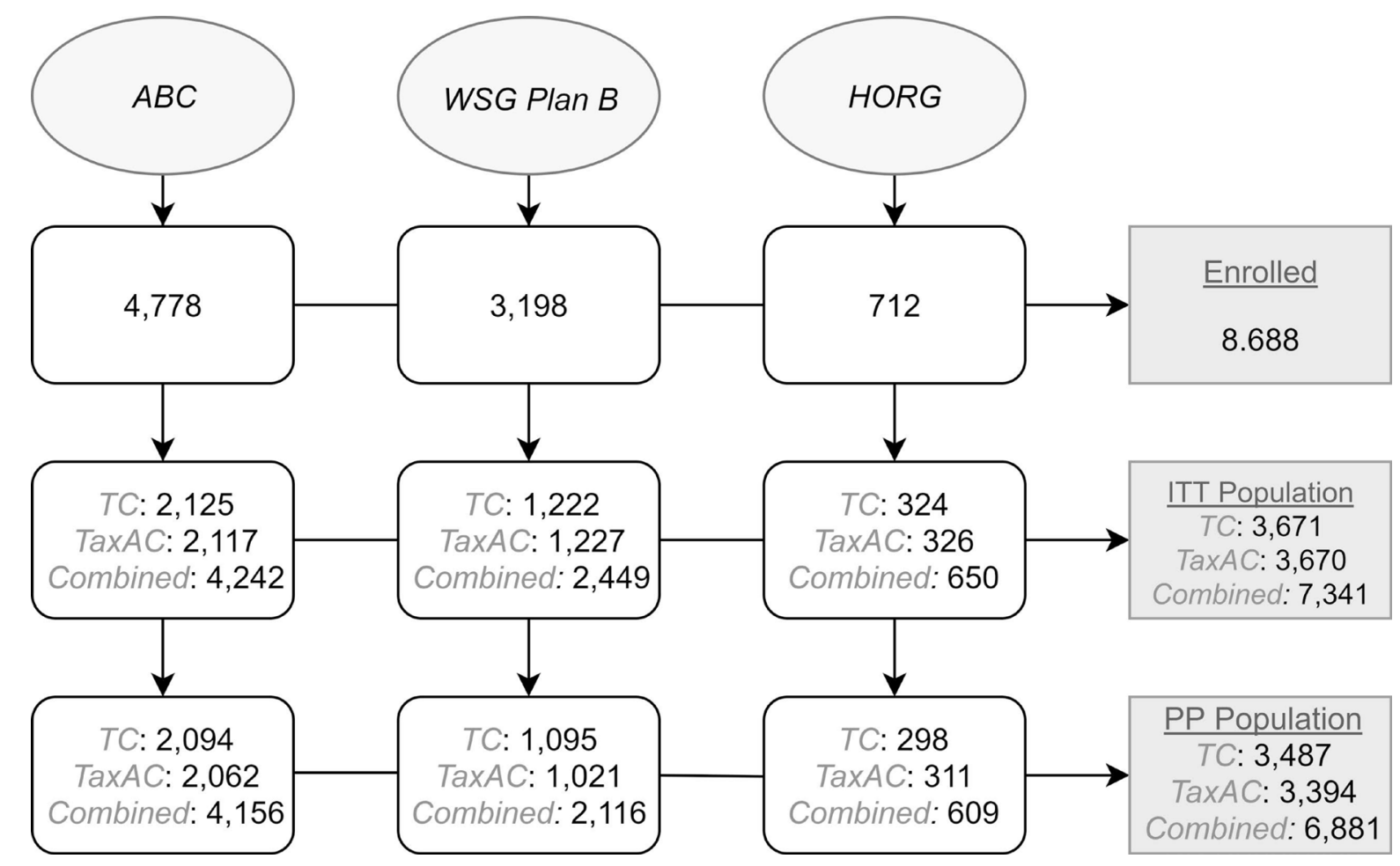

Figure 1: Flow diagram of included studies. ITT $=$ intention to treat, $\mathrm{PP}=$ per protocol, $\mathrm{TC}=$ taxane $\&$ cyclophosphamide, TaxAC $=$ taxane \& cyclophosphamide \& anthracycline. 
Table 1: Patient \& survival characteristics

\begin{tabular}{|c|c|c|c|c|c|c|c|c|c|c|c|c|c|c|c|}
\hline \multirow{2}{*}{ Studies } & \multirow{2}{*}{$\begin{array}{c}\begin{array}{c}\text { Median } \\
\text { follow-up }\end{array} \\
\text { (in years) }\end{array}$} & \multicolumn{2}{|c|}{ Grade $(n)$} & \multicolumn{2}{|c|}{$\begin{array}{l}\text { Endocrine } \\
\text { receptor }(n)\end{array}$} & \multicolumn{4}{|c|}{ Lymph nodes $(n)$} & \multicolumn{2}{|c|}{$\begin{array}{c}\text { Menopausal } \\
\text { status }(n)\end{array}$} & \multicolumn{2}{|c|}{ Surgery $(n)$} & \multicolumn{2}{|c|}{ DFS rates (\%) } \\
\hline & & $I / I I$ & III & Negative & Positive & No & N1 & $N 2$ & $N 3$ & Pre- & Post- & $B C S$ & Mastectomy & $T C$ & $\operatorname{Tax} A C$ \\
\hline Plan B & 5 & 1323 & 1034 & 445 & 2004 & 1441 & 832 & 135 & 41 & 868 & 1388 & 1985 & 459 & 90 & 90 \\
\hline$A B C$ & 3.3 & 1954 & 2120 & 1288 & 2868 & 1686 & 1836 & 478 & 165 & $\mathrm{n} / \mathrm{a}$ & $\mathrm{n} / \mathrm{a}$ & $\mathrm{n} / \mathrm{a}$ & $\mathrm{n} / \mathrm{a}$ & 88.2 & 90.7 \\
\hline HORG & 3.9 & 383 & 236 & 74 & 572 & $\mathrm{n} / \mathrm{a}$ & 414 & 179 & 57 & 199 & 451 & 326 & 324 & 91.1 & 89.5 \\
\hline Overall & $\mathrm{n} / \mathrm{a}$ & 3660 & 3390 & 1807 & 5444 & 3144 & 3074 & 812 & 264 & 1067 & 1839 & 2311 & 783 & 89.04 & 90.32 \\
\hline
\end{tabular}

N0 = zero lymph-nodes, N1 = 1 to 3 lymph-nodes, N2 = 4 to 9 lymph-nodes, N3 = 10 or more lymph-nodes.

Abbreviations: $\mathrm{BCS}=$ breast conserving surgery, DFS = disease free survival, TC = taxane \& cyclophosphamide, TaxAC $=$ taxane $\&$ cyclophosphamide $\&$ anthracycline.

Thrombocytopenia was rarely observed (TaxAC, $1.84 \%$; TC, $0.29 \%$ ), but was higher in the TaxAC group (grade $1-2$ : OR $=1.8, p=0.001$, grade $3-4$ : $\mathrm{OR}=6.4, p<0.001)$. Leukopenia, grade 3-4 events were mostly observed in the TaxAC group $(\mathrm{OR}=1.2$, $p=0.002)$, whereas febrile neutropenia grade 3-4 events were more common in the TC group $(\mathrm{OR}=0.74$, $p=0.005)$. Grade 3-4 immune-related or hypersensitivity reactions such as allergy $(\mathrm{OR}=0.35, p<0.001)$, rash $(\mathrm{OR}=0.4, p=0.002)$ and skin toxicity $(\mathrm{OR}=0.2$, $p<0.02$ ) were mainly associated with TC. Nausea (grade 1-2: OR $=1.7, p<0.001$; grade 3-4: OR = 2.6, $p<0.001$ ), vomiting (grade $1-2$ : $\mathrm{OR}=2.5, p<0.001$, grade $3-4$ : $\mathrm{OR}=2.2, p<0.001$ ), diarrhea (grade $1-2$ : $\mathrm{OR}=1.5, p<0.001)$, mucositis (grade $1-2: \mathrm{OR}=1.6$, $p=0.003$; grade 3-4: OR $=2.8, p<0.001)$, hand/foot syndrome (grade $3-4$ : OR $=1.9, p=0.01$ ), fatigue (grade $1-2: \mathrm{OR}=1.2, p=0.02$; grade $3-4: \mathrm{OR}=1.7, p<0.001)$, neurotoxicity (grade $3-4$ : $\mathrm{OR}=1.8, \mathrm{p}=0.001$ ), infection (grade $1-2: \mathrm{OR}=1.7, p=0.006)$, pain (grade $3-4$ : $\mathrm{OR}=1.3, p=0.04$ ) and cardiotoxicity (grade 3-4: $\mathrm{OR}=2.28, p=0.01)$ were observed at a higher rate in the TaxAC arm. Data concerning development of secondary malignancies have been so far reported only for $A B C$ trials, and as expected implicate the use of anthracycline containing regimens with the development of secondary hematologic malignancies.

\section{DISCUSSION}

To date several publications have addressed the appropriate adjuvant treatment for patients with EBC [6$10,14]$. Along with anthracyclines, taxanes are the most effective agents $[6,8,13,15]$. The incorporation of taxanes to anthracycline containing regimens seems to provide superior treatment benefits when compared to many other chemotherapy combinations, while superiority of TaxAC is not evident against TC [6]. Furthermore, concerns have been raised regarding the toxicity of triple combination regimens, implicating anthracycline use with cardiac toxicity and secondary hematological malignancies [5, $10,19]$.

The ABC trials [21], the HORG trial [5] and the WSG Plan B [22] trial have all set out to compare the efficacy of the TC regimen against TaxAC in the adjuvant setting of HER2-negative EBC. The anthracycline containing regimens were not found to be superior to $\mathrm{TC}$, while non-inferiority of TC was ambiguous in these individual studies. Therefore, our study by combining the available data from these RCTs, serves as the next

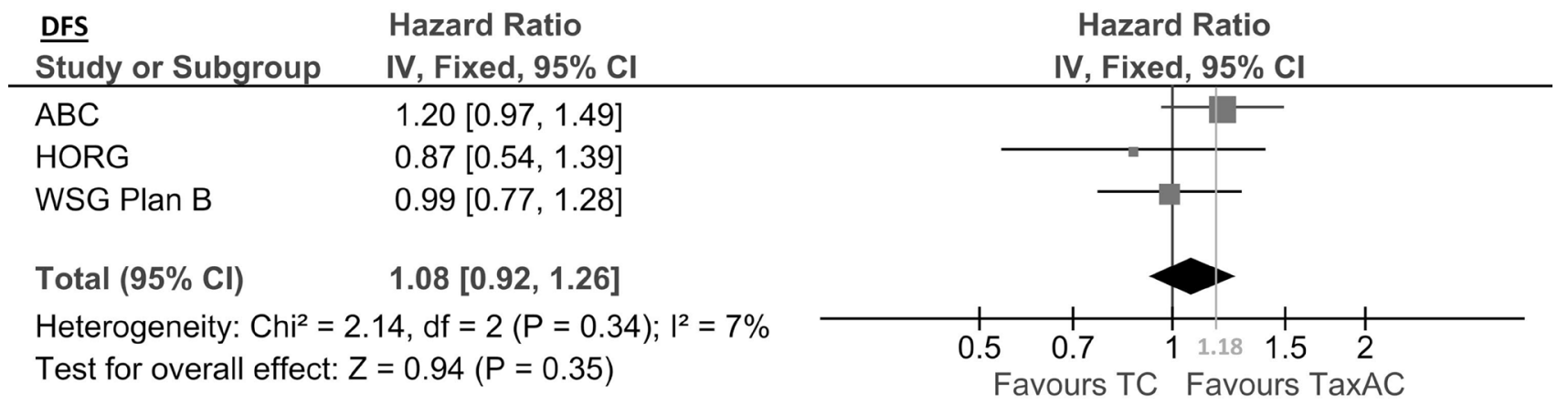

Figure 2: Disease free survival. DFS $=$ disease free survival, $\mathrm{CI}=$ confidence interval, $1.18=$ non-inferiority margin, $\mathrm{TC}=$ taxane $\&$ cyclophosphamide, TaxAC $=$ taxane $\&$ cyclophosphamide $\&$ anthracycline. 
Table 2: Toxicity profile

\begin{tabular}{|c|c|c|c|c|c|c|c|c|}
\hline & \multicolumn{4}{|c|}{ Grade 1-2 } & \multicolumn{4}{|c|}{ Grade 3-4 } \\
\hline & $\operatorname{Tax} A C \%$ & $T C \%$ & $O R$ & $p$ & $\operatorname{Tax} A C \%$ & $T C \%$ & $O R$ & $p$ \\
\hline Neutropenia & 5.69 & 5.02 & & 0.41 & 28.24 & 28.98 & & 0.48 \\
\hline Anemia & 28.56 & 23.42 & 1.3 & 0.001 & 1.34 & 0.87 & & 0.12 \\
\hline Thrombocytopenia & 5.63 & 3.14 & 1.8 & 0.001 & 1.84 & 0.29 & 6.4 & $<0.001$ \\
\hline Leucopenia & 1.82 & 2.73 & & 0.14 & 24.31 & 21.12 & 1.2 & 0.002 \\
\hline Febrile Neutropenia & 0.06 & 0.20 & & 0.32 & 4.64 & 5.84 & 0.74 & 0.005 \\
\hline Nausea & 21.77 & 14.25 & 1.7 & $<0.001$ & 3.10 & 1.19 & 2.6 & $<0.001$ \\
\hline Vomiting & 10.37 & 4.41 & 2.5 & $<0.001$ & 1.96 & 0.89 & 2.2 & $<0.001$ \\
\hline Diarrhea & 13.22 & 9.03 & 1.5 & $<0.001$ & 2.87 & 2.78 & & 0.8 \\
\hline Mucositis & 7.32 & 5.02 & 1.6 & 0.003 & 2.44 & 0.89 & 2.8 & $<0.001$ \\
\hline Constipation & 4.20 & 5.28 & & 0.16 & 0.33 & 0.13 & & 0.25 \\
\hline Allergy & 3.45 & 4.75 & & 0.07 & 0.67 & 1.90 & 0.35 & $<0.001$ \\
\hline Rash & 3.73 & 10.44 & 0.33 & $<0.001$ & 0.67 & 1.61 & 0.4 & 0.002 \\
\hline Skin toxicity & 2.64 & 3.88 & 0.67 & 0.058 & 0.13 & 0.66 & 0.2 & 0.02 \\
\hline Hand/Foot syndrome & 0.67 & 1.33 & & 0.7 & 1.23 & 0.66 & 1.9 & 0.013 \\
\hline Nail toxicity & 3.12 & 3.94 & & 0.2 & 0.06 & 0.13 & & 0.5 \\
\hline Conjuctivitis & 0.81 & 0.87 & & 0.86 & 0 & 0 & $n / a$ & $n / a$ \\
\hline Edema & 3.93 & 4.55 & & 0.4 & 0.27 & 0.33 & & 0.7 \\
\hline Fatigue & 27.61 & 24.02 & 1.2 & 0.026 & 5.26 & 3.17 & 1.7 & $<0.001$ \\
\hline Neurotoxicity & 5.08 & 5.08 & & 0.99 & 2.67 & 1.53 & 1.8 & 0.001 \\
\hline Infection & 5.92 & 3.50 & 1.7 & 0.006 & 4.27 & 4.22 & & 0.9 \\
\hline Arthralgia/myalgia & 10.27 & 16.23 & 0.59 & $<0.001$ & 2.85 & 2.47 & & 0.3 \\
\hline Pain & 11.75 & 12.56 & & 0.5 & 3.96 & 3.03 & 1.3 & 0.04 \\
\hline Cardiotoxicity & 0.88 & 1.07 & & 0.6 & 0.75 & 0.33 & 2.28 & 0.015 \\
\hline
\end{tabular}

Abbreviations: $\mathrm{OR}=$ odds ratio, $\mathrm{TC}=$ taxane $\&$ cyclophosphamide, TaxAC $=$ taxane $\&$ cyclophosphamide $\&$ anthracycline.

logical step in the evaluation process of TC. In our pooled-analysis the risk of recurrence and the risk of death seemed to favor TaxAC, without, however, providing statistical significance, meaning that no treatment arm was found to be superior to the other in terms of DFS or OS. Furthermore, despite lack of non-inferiority of TC, the present analysis demonstrated a small DFS deficit of $1.31 \%$ for TC and narrows the difference between the two chemotherapy regimens by further reducing the $95 \% \mathrm{CI}$ of the treatments effect on DFS and OS. The results of our study are in accordance with a recent meta-analysis which demonstrated equivalent efficacy of TC to anthracyclinebased regimens in terms of OS in the adjuvant setting, with a $43 \%$ probability of $\mathrm{TC}$ being the best, among a variety of chemotherapy agents [14].
With the exception of febrile neutropenia and the development of immune-related reactions, the overall pooled-toxicity profile favored TC. In general, taxanes are associated with toxicities such as myelosuppression and neuropathy [13]. In our pooled-analysis patients who received TaxAC experienced higher possibility of grade 3-4 neurotoxicity. Apart from neurotoxicity, cardiotoxicity prevailed with anthracycline use, while of note were the development of thrombocytopenia fatigue, nausea, vomiting, mucositis, pain and hand/ foot syndrome in the TaxAC arm. Febrile neutropenia was more common in the TC group, but we need the data of the percentage of patients who received prophylactic G-CSF in each group before coming to any conclusion. 
The cardiac toxicity of anthracyclines is well established and typically manifests as congestive heart failure, may develop up to 10 or 15 years after completion of treatment [5, 8, 20, 23]. Some populations are more susceptible to anthracycline toxicity [8], among them are women with left-sided tumors due to the administration of adjuvant radiotherapy $[5,24]$ and there is no doubt that increased age is oftenly associated with decreased physiological reserves and increased likelihood of comorbidities such as cardiovascular disease [13, 25, 26]. Finally, the concurrent administration of anthracyclines and taxane has been associated with the highest risk of hospitalization during therapy for EBC [15], reflecting an additional burden to patients and increased costs.

Our analysis has several limitations. Although no heterogeneity was found between the trials, the anthracycline-based regimens were different. The ABC trials used a DFS endpoint that included only invasive disease, excluding ductal carcinoma in situ as a recurrence endpoint. Also, we observed a discord between the trials concerning the definition of the high-risk EBC population. Finally, our study's inability to confirm non-inferiority of TC might stem from the particularly conservative threshold that we choose and further analysis might be needed to determine a more fitting boundary of inferiority.

Although our pooled analysis failed to show noninferiority of the TC regimen compared to TaxAC, we demonstrated that the absolute difference in DFS is relatively limited $(1.28 \%)$. Whether this difference in clinically meaningful has to be discussed with each individual patient taking into account the estimated risk of disease relapse, the acute and late toxicities of TaxAC and of course patient's perspective and wishes.

\section{MATERIALS AND METHODS}

\section{Criteria}

We reviewed the published literature and the proceedings of major oncology meetings for studies that fulfill the following criteria: 1) randomized controlled trials comparing the non-inferiority of the TC regimen to the 'standard of care' TaxAC, 2) early stage breast cancer, 3) HER2-negative adenocarcinoma and 4) high risk of recurrence. High risk was heterogenous in the trials and could be defined by any of the following conditions; the presence of lymph node metastasis, or, in the absence of lymph node disease (i.e. N0) patients would have negative endocrine receptors (ER), or, tumor size would be $>2.0$ $\mathrm{cm}$, or $\mathrm{pT} \geq 2$, or, smaller tumors (i.e. T1c) in the context of grade 3 histology or high OncotypeDX score $(\geq 25$ for B-46-I/07132 and B-49, or $\geq 31$ for USOR 06-090). Finally, the study population consisted of women with an Eastern Cooperative Oncology Group performance status of 0 or 1 , or with adequate hematopoietic, hepatic, and renal functions and a left ventricular ejection fraction of at least $50 \%$.

Three trials were identified: the WSG Plan B trial, the Hellenic trial conducted by HORG and the joined efficacy analysis of the ABC trials. The ABC trials consisted of three individual, sequentially conducted, open label, randomized phase III trials, composed from USOR 06-090, NSABP-USOR and USOR 06-0690; the $\mathrm{ABC}$ trials efficacy data were never analyzed individually before they were combined. The present analysis was concluded by pooling data from all the above "five" randomized controlled trials (RCTs).

\section{Outcomes}

The objective of this study was to address whether $\mathrm{TC}$ is non-inferior to TaxAC in the adjuvant setting of patients with HER2-negative, breast cancer. The outcomes analyzed were DFS and OS; DFS was considered the primary outcome. Recurrence of the primary cancer (local or distant), diagnosis of a second primary, or death from any cause were considered as DFS events. Overall survival was defined from the time of randomization to death from any cause. We analyzed separately the effect of the treatment on DFS in patients with lymph node-negative disease. The combined effect of the treatment on DFS or OS was expressed as a pooled Hazard Ratio (HR) of the anthracycline-free TC arm over the TaxAC arm. Thus, a HR over 1 would favor patients receiving the TaxAC regimen, whereas a $\mathrm{HR}<1$ favors the anthracycline-free treatment.

Adverse events (AE) from the included studies were pooled to study differences in the toxicity profile between the treatment regimens. The risk of any AE was expressed as odds ratio (OR) by approximating the number of patients experiencing the $\mathrm{AE}$ in the anthracycline-free $\mathrm{TC}$ treatment arm by the population of that arm over the number of patients experiencing the $\mathrm{AE}$ in the TaxAC treatment arm by the population of that arm. Thus, an OR over 1 indicated higher risk of toxicity for the TaxAC arm, whereas $\mathrm{OR}<1$ indicated higher risk of an AE for the TC group.

\section{Data extraction}

The following characteristics were extracted from each published report: author's name, year of publication, study design, regimen details, sample size and allocated patients, tumor characteristics (grading, ER-status), lymph node infiltration, menopausal status, type of resection, median follow-up, AEs, HRs along with 95\% CIs and survival percentages (OS and DFS) at each study's designated time point (i.e. a 5, 4 and 3 year survival rate was designated in the Plan B, the ABC and the HORG trials respectively). Extraction was performed only for published information. Intention to treat data were used for the pooled analysis. 


\section{Statistical analysis}

A HR of 1.18 for TC versus TaxAC, which corresponded to the threshold defined in the $\mathrm{ABC}$ trials, was chosen to demonstrate inferiority, as it was the most conservative measure among the included studies. For non-inferiority to be established, the upper boundary of the $95 \% \mathrm{CI}$ for the treatment effect on DFS of the TC over the TaxAC arm, should be equal or less to 1.18.

The Inverse-Variance (IV) statistical method was applied for calculation of the pooled HRs. Percentages for survival (DFS and OS), were pooled according to arcsine square root transformation (Freeman and Tukey, 1950). Between studies heterogeneity was evaluated with Cochran's $Q$ test; in case of statistically significant heterogeneity $(Q$ test $P<0.1)$ the Random Effects (RE) model was reported; otherwise the Fixed Effects (FE) model was adopted to estimate the pooled ratios. Higgins $I^{2}$-statistic was used to quantify the degree of of inconsistency in the results. Visual inspection of a Standard Error/Effect Size funnel plot of the primary outcome as well as estimation of Egger's test [27], were employed to assess publication bias. Statistical significance was set at the two-sided 0.05 level. RevMan software V5.3 and MedCalc V16.4 were used for the completion of the pooled data analysis.

Database screening/study selection, data extraction and quality assessment were performed each time by two researchers ( $\mathrm{PN}$ and NS respectively); all researchers worked independently and in a blinded manner. Any disagreement was resolved by a third author (ES). All authors had full access to all data in the study and take responsibility for the integrity of the data and accuracy of the data analysis.

\section{Author contributions}

ES conceived the idea; PN and NS collected the data; PN, EZ performed the analysis; PN, SA and ES drafted the manuscript. All the authors reviewed and commented and approved the final version of the manuscript All authors had full access to all data in the study and take responsibility for the integrity of the data and accuracy of the data analysis.

\section{CONFLICTS OF INTEREST}

The authors declare that there are no conflicts of interest regarding the publication of this article.

This research did not receive any specific grant from funding agencies in the public, commercial, or not-forprofit sectors.

\section{FUNDING}

The study was funded by the Hellenic Society for Medical Oncology HeSMO.

\section{REFERENCES}

1. Breast cancer incidence (invasive) statistics. Cancer Recearch UK. Available from: https://www.cancerresearchuk.org/ health-professional/cancer-statistics/statistics-by-cancer-type/ breast-cancer/incidence-invasive\#heading-Three.

2. Torre LA, Bray F, Siegel RL, Ferlay J, Lortet-Tieulent J, Jemal A. Global cancer statistics, 2012. CA Cancer J Clin. 2015; 65:87-108.

3. Iqbal J, Ginsburg O, Rochon PA, Sun P, Narod SA. Differences in breast cancer stage at diagnosis and cancerspecific survival by race and ethnicity in the United States. JAMA. 2015; 313:165-73.

4. Early-stage breast cancer. NCI Dictionary of Cancer Terms: NIH National Cancer Institut [cited 2018 15.08]; Available from: https://www.cancer.gov/publications/dictionaries/ cancer-terms/def/early-stage-breast-cancer.

5. Mavroudis D, Matikas A, Malamos N, Papakotoulas P, Kakolyris S, Boukovinas I, Athanasiadis A, Kentepozidis N, Ziras N, Katsaounis P, Saloustros E, Georgoulias V; Breast Cancer Investigators of the Hellenic Oncology ResearchGroup (HORG), Athens, Greece. Dose-dense FEC followed by docetaxel versus docetaxel plus cyclophosphamide as adjuvant chemotherapy in women with HER2-negative, axillary lymph node-positive early breast cancer: a multicenter randomized study by the Hellenic Oncology Research Group (HORG). Ann Oncol. 2016; 27:1873-8.

6. De Laurentiis M, Cancello G, D'Agostino D, Giuliano M, Giordano A, Montagna E, Lauria R, Forestieri V, Esposito A, Silvestro L, Pennacchio R, Criscitiello C, Montanino A, et al. Taxane-based combinations as adjuvant chemotherapy of early breast cancer: a meta-analysis of randomized trials. J Clin Oncol. 2008; 26:44-53.

7. Bonilla L, Ben-Aharon I, Vidal L, Gafter-Gvili A, Leibovici L, Stemmer SM. Dose-dense chemotherapy in nonmetastatic breast cancer: a systematic review and metaanalysis of randomized controlled trials. J Natl Cancer Inst. 2010; 102:1845-54.

8. Greene J, Hennessy B. The role of anthracyclines in the treatment of early breast cancer. J Oncol Pharm Pract. 2015; 21:201-12.

9. Early Breast Cancer Trialists' Collaborative Group (EBCTCG). Effects of chemotherapy and hormonal therapy for early breast cancer on recurrence and 15-year survival: an overview of the randomised trials. Lancet. 2005; 365:1687-717. 
10. Peto R, Davies C, Godwin J, Gray R, Pan HC, Clarke M, Cutter D, Darby S, McGale P, Taylor C, Wang YC, Bergh J, Di Leo A, et al; Early Breast Cancer Trialists' Collaborative Group (EBCTCG). Comparisons between different polychemotherapy regimens for early breast cancer: metaanalyses of long-term outcome among 100,000 women in 123 randomised trials. Lancet. 2012; 379:432-44.

11. Tufia C. Haddad CLL. Breast Cancer. In: Hensley ML, ed. ASCO-SEP. 2016.

12. Poole CJ, Earl HM, Hiller L, Dunn JA, Bathers S, Grieve RJ, Spooner DA, Agrawal RK, Fernando IN, Brunt AM, O'Reilly SM, Crawford SM, Rea DW, et al; NEAT Inve stigators and the SCTBG. Epirubicin and cyclophosphamide, methotrexate, and fluorouracil as adjuvant therapy for early breast cancer. N Engl J Med. 2006; 355:1851-62.

13. Biganzoli L, Aapro M, Loibl S, Wildiers H, Brain E. Taxanes in the treatment of breast cancer: Have we better defined their role in older patients? A position paper from a SIOG Task Force. Cancer Treat Rev. 2016; 43:19-26.

14. Fujii T, Le Du F, Xiao L, Kogawa T, Barcenas CH, Alvarez RH, Valero V, Shen Y, Ueno NT. Effectiveness of an Adjuvant Chemotherapy Regimen for Early-Stage Breast Cancer: A Systematic Review and Network Meta-analysis. JAMA Oncol. 2015; 1:1311-8.

15. Ruddy KJ, Van Houten HK, Sangaralingham LR, Freedman RA, Thompson CA, Hashmi SK, Jemal A, Haddad TC, Mougalian S, Herrin J, Gross C, Shah N. Impact of treatment regimen on acute care use during and after adjuvant chemotherapy for early-stage breast cancer. Breast Cancer Res Treat. 2017; 164:515-25.

16. Jones S, Holmes FA, O'Shaughnessy J, Blum JL, Vukelja SJ, McIntyre KJ, Pippen JE, Bordelon JH, Kirby RL, Sandbach J, Hyman WJ, Richards DA, Mennel RG, et al. Docetaxel With Cyclophosphamide Is Associated With an Overall Survival Benefit Compared With Doxorubicin and Cyclophosphamide: 7-Year Follow-Up of US Oncology Research Trial 9735. J Clin Oncol. 2009; 27:1177-83.

17. Jones SE, Savin MA, Holmes FA, O'Shaughnessy JA, Blum JL, Vukelja S, McIntyre KJ, Pippen JE, Bordelon JH, Kirby R, Sandbach J, Hyman WJ, Khandelwal P, et al. Phase III trial comparing doxorubicin plus cyclophosphamide with docetaxel plus cyclophosphamide as adjuvant therapy for operable breast cancer. J Clin Oncol. 2006; 24:5381-7.

18. Mackey JR, Pienkowski T, Crown J, Sadeghi S, Martin M, Chan A, Saleh M, Sehdev S, Provencher L, Semiglazov V, Press MF, Sauter G, Lindsay M, et al; Translational Research In Oncology (TRIO)/ Breast Cancer International Research Group (BCIRG)-005 investigators. Long-term outcomes after adjuvant treatment of sequential versus combination docetaxel with doxorubicin and cyclophosphamide in node-positive breast cancer: BCIRG-005 randomized trial. Ann Oncol. 2016; 27:1041-7.

19. Henderson IC, Berry DA, Demetri GD, Cirrincione CT, Goldstein LJ, Martino S, Ingle JN, Cooper MR, Hayes DF, Tkaczuk KH, Fleming G, Holland JF, Duggan DB, et al. Improved outcomes from adding sequential Paclitaxel but not from escalating Doxorubicin dose in an adjuvant chemotherapy regimen for patients with node-positive primary breast cancer. J Clin Oncol. 2003; 21:976-83.

20. Mackey JR, Martin M, Pienkowski T, Rolski J, Guastalla JP, Sami A, Glaspy J, Juhos E, Wardley A, Fornander T, Hainsworth J, Coleman R, Modiano MR, et al; TRIO/ BCIRG 001 investigators. Adjuvant docetaxel, doxorubicin, and cyclophosphamide in node-positive breast cancer: 10-year follow-up of the phase 3 randomised BCIRG 001 trial. Lancet Oncol. 2013; 14:72-80.

21. Blum JL, Flynn PJ, Yothers G, Asmar L, Geyer CE Jr, Jacobs SA, Robert NJ, Hopkins JO, O'Shaughnessy JA, Dang CT, Gomez HL, Fehrenbacher L, Vukelja SJ, et al. Anthracyclines in Early Breast Cancer: The ABC TrialsUSOR 06-090, NSABP B-46-I/USOR 07132, and NSABP B-49 (NRG Oncology). J Clin Oncol. 2017; 35:2647-55.

22. Harbeck N, Gluz O, Clemens MR, Malter W, Reimer T, Nuding B, Aktas B, Stefek A, Pollmanns A, Lorenz-Salehi F, Uleer C, Krabisch P, Kummel S, et al. Prospective WSG phase III PlanB trial: Final analysis of adjuvant $4 x E C \rightarrow 4 x$ doc vs. $6 \mathrm{x}$ docetaxel/cyclophosphamide in patients with high clinical risk and intermediate-to-high genomic risk HER2-negative, early breast cancer. Journal of Clinical Oncology. 2017; 35:504.

23. Steinherz LJ, Steinherz PG, Tan CT, Heller G, Murphy ML. Cardiac toxicity 4 to 20 years after completing anthracycline therapy. JAMA. 1991; 266:1672-7.

24. Darby SC, McGale P, Taylor CW, Peto R. Long-term mortality from heart disease and lung cancer after radiotherapy for early breast cancer: prospective cohort study of about 300,000 women in US SEER cancer registries. Lancet Oncol. 2005; 6:557-65.

25. Lichtman SM, Wildiers H, Chatelut E, Steer C, Budman D, Morrison VA, Tranchand B, Shapira I, Aapro M; International Society of Geriatric Oncology Chemotherapy Taskforce. International Society of Geriatric Oncology Chemotherapy Taskforce: Evaluation of Chemotherapy in Older Patients-An Analysis of the Medical Literature. Journal of Clinical Oncology. 2007; 25:1832-43.

26. Wildiers H, Highley MS, de Bruijn EA, van Oosterom AT. Pharmacology of Anticancer Drugs in the Elderly Population. Clinical Pharmacokinetics. 2003; 42:1213-42.

27. Egger M, Davey Smith G, Schneider M, Minder C. Bias in meta-analysis detected by a simple, graphical test. BMJ. 1997; 315:629-34. 